\title{
O Enfermeiro e a Inclusão do Doente Mental na Atenção Básica
}

\author{
Amaral, Natalia Valeria Alves do; Friestino, Jane Kelly; Cruz, Vanessa da \\ PUC Campinas - nataliaamaral21@hotmail.com
}

INTRODUÇÃO: para se construir um sistema de serviços de saúde voltado para a democracia, à universalidade igualitária e integral, é necessário a constituição de um processo social e político que se realiza por meio de formulação de políticas públicas dirigidas à saúde. em saúde mental devemos visar fatores relevantes para a reflexão crítica sobre os processos de trabalho, objetivando a produção de novos conhecimentos e ao desenvolvimento de novas práticas de saúde consoantes com os princípios e diretrizes do SUS. OBJETIVO: Possibilitar ao doente mental o acesso à informação sobre as doenças crônico-degenerativas, discutindo de forma humanizada a abordagem sobre o tema. MÉTODOS: Ocorreu durante a realização do Estágio curricular em Saúde Coletiva do 8o período do curso de Enfermagem, em um Centro de Saúde da região Noroeste do município de Campinas. Foram utilizadas estratégias de educação em saúde para promoção e prevenção da saúde. o período de realização foi entre outubro e novembro de 2013, com encontros semanais com cada grupo. a equipe de atuação foi constituída por 02 acadêmicas de enfermagem e 01 médico e 01 terapeuta ocupacional. Foram abordados temas como Hipertensão Arterial, Diabetes Mellitus, Colesterol e Crises convulsivas. em todos os encontros foram ampliadas as escutas em grupo, com discussões diversificadas, removendo a terapêutica voltada apenas para os sinais e sintomas e também uma ação que valorize a subjetividade do indivíduo. Além disso, em cada grupo foram realizadas aferições de SSVV e levantamentos para verificar a necessidade da realização de exames laboratoriais. RESULTADOS: No total foram quatro grupos abordados: Grupo Esperança, composto por 8 pacientes; Grupo Esperança II, com 11 pacientes; Grupo Alegria, 7 pacientes e Grupo Colibri, 16 pacientes. a faixa etária variou entre 22 e 78 anos. Foram espaços abertos onde os pacientes colocavam suas opiniões e dúvidas e trocavam experiências. de uma forma geral, esse público apresentou dúvidas interessantes e bastante significativas para uma melhor qualidade de vida, além de receber de forma harmoniosa a equipe que está ali visando melhorias em suas práticas de vida cotidianas. CONCLUSÕES: o projeto voltou-se para a conquista da cidadania do doente mental, e assim uma compreensão de que a educação pode tornar-se um dos instrumentos de emancipação dos sujeitos. o doente mental necessita ser tratado em um todo, congregando também questões físicas nas quais não se tem muito foco, visto o seu psique ser o objetivo central do seu ser. Este público por sua vez, está disposto a um melhor entendimento sobre sua saúde, pois possuem indagações, medos e anseios sobre as possíveis complicações advindas de suas bases orgânicas. no entanto faz- se necessário uma melhor educação em saúde para estas pessoas, com tratamentos holísticos e diferenciados, com ações mais concisas e claras.

Amaral, Natalia Valeria Alves do; Friestino, Jane Kelly; Cruz, Vanessa da. O Enfermeiro e a Inclusão do Doente Mental na Atenção Básica. In: Anais do Congresso Internacional de Humanidades \& Humanização em Saúde [= Blucher Medical Proceedings, num.2, vol.1]. São Paulo: Editora Blucher, 2014. ISSN 2357-7282

DOI 10.5151/medpro-cihhs-10210 